\title{
PERGAMON
}

www.elsevier.com/locate/watres

\section{CO-CONDITIONING AND DEWATERING OF CHEMICAL SLUDGE AND WASTE ACTIVATED SLUDGE}

\author{
G. R. CHANG ${ }^{1}$, J. C. $\mathrm{LIU}^{1 *}$ and D. J. LEE ${ }^{2}$ \\ ${ }^{1}$ Department of Chemical Engineering, National Taiwan University of Science and Technology, \\ 43 Keelung Road, Section 4, Taipei 106, Taiwan and ${ }^{2}$ Department of Chemical Engineering, \\ National Taiwan University, 1 Roosevelt Road, Section 4, Taipei 106, Taiwan
}

(First received 17 August 1999; accepted in revised form 17 June 2000)

\begin{abstract}
The conditioning and dewatering behaviors of chemical and waste activated sludges from a tannery were studied. Capillary suction time (CST), specific resistance to filtration (SRF), and bound water content were used to evaluate the sludge dewatering behaviors. Zeta potentials were also measured. Experiments were conducted on each sludge conditioned and dewatered separately, and on the sludge mixed at various ratios. Results indicate that the chemical sludge was relatively difficult to be dewatered, even in the presence of polyelectrolyte. When the waste activated sludge was mixed with the chemical sludge at ratios of $1: 1$ and $2: 1$, respectively, the dewaterability of chemical sludge improved remarkably while the relatively better dewaterability of the waste activated sludge deteriorated only to a limited extent. As the mixing ratios became $4: 1$ and $8: 1$, the dewaterability of the mixed sludge was equal to that of the waste activated sludge. The optimal polyelectrolyte dosage for the mixed sludge was equal to or less than that of the waste activated sludge. It is proposed that the chemical sludges act as skeleton builders that reduce the compressibility of the mixed sludge whose dewaterability is enhanced. Bound water contents of sludge decreased at low polyelectrolyte dosage and were not significantly affected as polyelectrolyte dosage increased. Advantages and disadvantages of co-conditioning and dewatering chemical sludge and waste activated sludge were discussed. (C) 2001 Elsevier Science Ltd. All rights reserved
\end{abstract}

Key words - bound water, capillary suction time (CST), conditioning, dewatering, polyelectrolyte, sludge, specific resistance to filtration (SRF), tannery

\section{INTRODUCTION}

The activated sludge process is the most important treatment method for a wide range of wastewaters. However, sludge from wastewater treatment plants usually exhibits resistance to mechanical dewatering. The chemicals are therefore added to the wastewater sludge as conditioner to enhance dewaterability. Nevertheless, sludge dewatering has been pointed out as the most expensive and least understood process (Bruus et al., 1992). The characteristics of the conditioning and dewatering of sludge have received extensive study recently. The sludges include sediments from clarifiers, screenings, grit, scum, and septage. Depending on sources of generation, they are classified as primary sludge, biological sludge and chemical sludge. Both chemical and biological sludges could be generated at the same site, since pretreatment of industrial wastewaters has been widely practiced for pollution control. The wastewater originating from the industries contains several

*Author to whom all correspondence should be addressed. Tel.: + 1-886-2-2737-6627; fax: + 1-886-2-2737-6644; e-mail: liu@ch.ntust.edu.tw conventional parameters as well as a number of micropollutants. It is therefore common to have a physicochemical pretreatment unit process in conjunction with a biological unit process, so that the micropollutants can be removed and effective treatment can be achieved. Consider tannery wastewater as an example; chemical precipitation is required to remove the chromium and chemical oxygen demand (COD) from wastewater before the wastewater flows into a biological treatment unit (Tunay et al., 1994; Ates et al., 1997).

The wastewater composition, chemicals used, and treatment units mainly determine the amount and properties of chemical sludge. There are carbonate precipitates, phosphate precipitates, hydroxide precipitates, inert solids, and polymer solids (Cheremisinoff, 1994). The chemical sludge from a tannery, for example, consists mostly of oil and grease, magnesium, calcium and chromium hydroxides precipitates, inert solids, and debris from pig hide (Martin and Parkin, 1986; Langlais and Shivas, 1989; Chuan and Liu, 1996).

Biological sludge is relatively hard to be dewatered compared with the primary sludge. It is due to the small size of colloidal and fine particles that flow 
through the primary clarifier and are eventually removed in the secondary clarifier (Cheremisinoff, 1994). Activated sludge is a heterogeneous mixture of particles, microorganisms, colloids, organic polymers and cations (Jorand et al., 1995). The biological cells contain $99 \%$ water which can be divided into free water, surface water, interstitial water and bound water (Vesilind and Martel, 1990).

In recent years, polyelectrolytes have become a primary choice as conditioner for sludge dewatering operations. Conventionally, a cationic polyelectrolyte is used in the waste activated sludge conditioning in which two main mechanisms are involved: charge neutralization and interparticle bridging (Bohm and Kulicke, 1997). Good control of polyelectrolyte dose is critical in the sludge conditioning, since an overdose will increase the cost and reduce sludge dewaterability. The optimal polyelectrolyte dosage is usually associated with the colloidal surface of minimum surface charge and a tendency to aggregate to form large floc (Christensen et al., 1993). Since some of the chemical sludges are positively charged, an anionic polyelectrolyte may be used as the conditioner to facilitate the polymer adsorption onto the sludge surfaces. For the wastewater treatment plants that generate both chemical and wasteactivated sludges on-site, questions arise whether it is wise to co-condition both the sludge, or rather treat them separately. Only very limited information is available. It has been indicated that wastewater containing fiber from a pulp and paper mill enhances the dewaterability of the sludge from a POTW (Eckenfelder Jr. and Musterman, 1994). Besides, it is recommended, without detailed elaboration, to dewater chemical and waste activated sludges together, so that better dewatering efficiency can be achieved (WPCF, 1983; Cheremisinoff, 1994). In fact, very little is known about the conditioning and dewatering behaviors of the mixture of chemical and waste activated sludges. Yet, in a survey among industrial wastewater treatment plants in Taiwan, it is found that co-conditioning and dewatering of the chemical and biological sludges is a common practice.

In the current study, basic properties of the chemical and the waste activated sludges from a tannery were first characterized. The conditioning and dewatering of each sludge were investigated. The co-conditioning and dewatering behaviors of mixed chemical and waste activated sludges were then examined and compared. The major objectives are to study if it is advantageous in co-conditioning and dewatering the chemical and waste activated sludges from a tannery, and to elucidate the mechanisms in conditioning and dewatering of the mixed sludge.

\section{MATERIALS AND METHODS}

The sludge samples were obtained from the Chen-Sam tannery located in Pintung, Taiwan. The Chen-Sam tannery manufactures leather using pig hide as the raw material. Its production processes are soaking-liming-deliming, batingtanning-neutralization-dyeing, and fatliquoring. Its wastewater treatment plant consists of a physicochemical process with coagulation-flocculation and sedimentation units, and an activated sludge process. The process flow chart is shown in Fig. 1. The amount of sludge generated is ca 4-6 metric tons (dry weight) per month. The release behaviors of chromium from the chemical sludge have been described

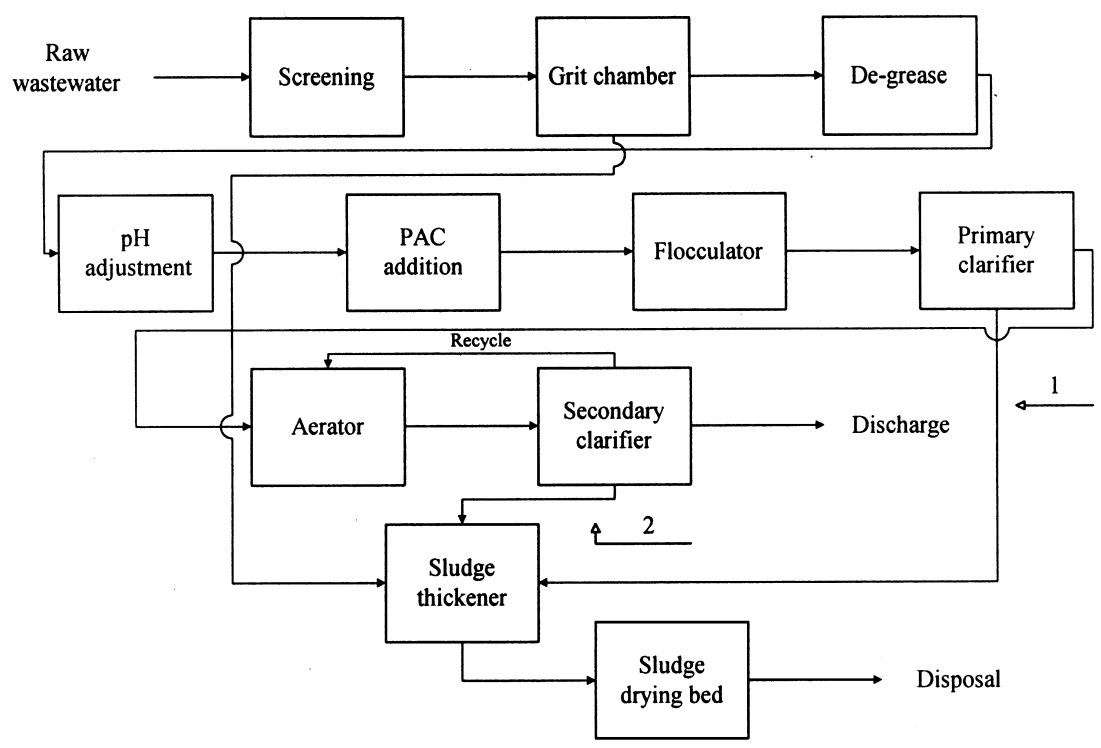

1. Where chemical sludge was sampled

2. Where waste activated sludge was sampled

Fig. 1. Flow chart of the wastewater treatment process in the Chen-Sam Corp. 
Table 1. Basic properties of the waste activated, chemical and the mixed sludges

\begin{tabular}{|c|c|c|c|c|c|c|}
\hline Parameter & WAS $^{\mathrm{a}}$ & $\mathrm{CS}^{\mathrm{b}}$ & $1: 1^{\mathrm{c}}$ & $2: 1$ & $4: 1$ & $8: 1$ \\
\hline $\mathrm{SS}(\mathrm{mg} / \mathrm{L})$ & 4308 & 83,944 & 44,126 & 30,853 & 20,235 & 13,156 \\
\hline$\rho_{\mathrm{s}}\left(\mathrm{g} / \mathrm{cm}^{3}\right)$ & 1.59 & 1.51 & 1.47 & 1.49 & 1.50 & 1.54 \\
\hline dAvE $(\mu \mathrm{m})$ & 30.6 & 43.2 & $-^{\mathrm{d}}$ & - & - & - \\
\hline
\end{tabular}

${ }^{\text {a }}$ Waste activated sludge.

${ }^{\mathrm{b}}$ Chemical sludge.

${ }^{\mathrm{c}}$ Mixed sludge with the volumetric ratio of waste activated sludge: chemical sludge.

${ }^{\mathrm{d}}$ Measurement was not conducted.

(Chuan and Liu, 1996). Currently, the chemical and waste activated sludges are co-thickened and pumped to the sludge drying bed, and dried by sunshine. Limited by the space available, the tannery plans to replenish with mechanical dewatering equipment. The chemical sludge was sampled from the bottom of the primary clarifier, and the wasteactivated sludge was sampled from the bottom of the secondary clarifier. Both the sludges were placed in $50-\mathrm{L}$ polyethylene tanks and kept in the refrigerator at $4{ }^{\circ} \mathrm{C}$ after being brought back to our laboratory. All experiments were completed within one week to minimize possible changes in properties of the sludge during storage.

The suspension solid (SS) of the sludge samples were determined using standard methods (APHA, 1990). The dry solid density, $\rho_{\mathrm{s}}$, was determined by a pycnometer (Pycnometer, Accupyc 1130). The values of $\mathrm{pH}$ were measured by immersing the electrode (Jenco, 6209) $2 \mathrm{~cm}$ below the sludge-air interface. The zeta potential was measured using a laser electrophoresismeter (Photal, Leza$600)$. The flocs were first shaken in order to break them into small particles and the supernatant was sampled $10 \mathrm{~min}$ afterwards for zeta potential measurement. The sludge size was determined by a particle size analyzer (Malvern, 2600C). The average size was $30.6 \mu \mathrm{m}$ for the wasteactivated sludge and $43.2 \mu \mathrm{m}$ for the chemical sludge. In making mixed sludge samples, different volumetric ratios of waste activated and chemical sludges were placed in a 2-L flask and stirred at $400 \mathrm{rpm}$ for $45 \mathrm{~s}$. The basic properties of sludge are listed in Table 1.

A cationic polyelectrolyte (Oya, CN60) with a molecular weight of 10 million and a charge density of $80 \%$ was used as the conditioner. Stock solution of the polyelectrolyte $(2000 \mathrm{mg} / \mathrm{L})$ was prepared by placing a weighed amount of solid polyelectrolyte in a volumetric flask, filled with distilled water, and stirred (Fargo, MS-211) at $100 \mathrm{rpm}$ for $15 \mathrm{~h}$. Stock solutions of polyelectrolyte were prepared and aged for at least $24 \mathrm{~h}$ before use. A stainless-steel tube with an inner radius of $0.535 \mathrm{~cm}$ and a Whatman ${ }^{\#} 17$ filter paper were used in the CST test. The time of filtrate wetting the filter paper from the radius of 1.0 to $3.0 \mathrm{~cm}$ was measured as CST. The measurement of CST was triplicated and the average value was taken. The expression method was used in the determination of SRF and the bound water content. The pressure utilized in the test was controlled at $3000 \mathrm{psi}$. The experimental set-up and procedures can be found in our previous work (Chen et al., 1997). A conventional jarstirring device was used to mix the sludge. The sludge samples of $500 \mathrm{~mL}$ in 1-L beaker each were used in the experiments. The polyelectrolyte of the pre-calculated dose was added and mixed at $100 \mathrm{rpm}$ for $45 \mathrm{~s}$, followed by $90 \mathrm{~s}$ at $45 \mathrm{rpm}$.

\section{RESULTS AND DISCUSSION}

\section{Zeta potential}

Figure 2 demonstrates that the zeta potential of the chemical sludge was originally equal to $0.5 \mathrm{mV}$. The

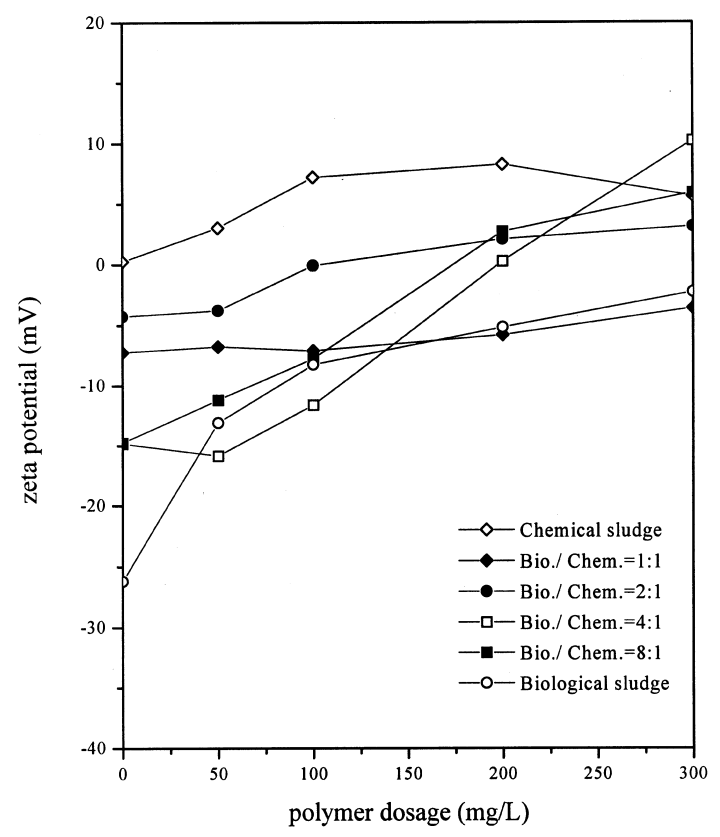

Fig. 2. Zeta potential of sludge as a function of polyelectrolyte dosage $(\mathrm{mg} / \mathrm{L})$.

coagulant used probably caused the nearly neutral value. Upon the addition of the cationic polyelectrolyte, it shifted slightly to positive values ranging from 6 to $8 \mathrm{mV}$. The surfaces of the waste activated sludge were originally negatively charged with the zeta potential of $-26 \mathrm{mV}$. The zeta potential was significantly affected by polyelectrolyte, as it shifted towards the less negative values as polyelectrolyte dose increased. However, no charge reversal was found. The mixed sludge samples with different ratios of waste activated sludge to chemical sludge showed similar behaviors, i.e., the zeta potential increased with increasing polyelectrolyte concentration and different iso-electric points (EPS) could be found. Though some anomalies were observed, the zeta potential of mixed sludge samples generally followed the lever rule, i.e., the zeta potential was determined by the fraction of composition. The adsorption of the cationic polyelectrolyte onto the chemical sludge seems to be mainly driven by hydrogen bonding and the van der Waals force, owing to the high molecular weight of the polyelectrolyte (Somasundaran and $\mathrm{Yu}$, 1994; Somasundaran and Krishnakumar, 1997). Due to steric hindrance and electrostatic repulsion, it was 
difficult for the polyelectrolyte to adsorb on the loops, tails or surfaces of the particles at higher concentration (Somasundaran and Krishnakumar, 1997). On the other hand, the adsorption of the cationic polyelectrolyte onto the waste activated sludge surfaces could be attributed to the electrostatic attractive force, resulting in the charge neutralization. It was found that by mixing both waste activated and chemical sludges together, certain electrostatic repulsive force among the sludge particles could be reduced as evidenced by the zeta potential data. This is in conformity with previous literature which shows that from an electrokinetic point of view it is beneficial for dewatering by mixing the biological and chemical sludges together (WPCF, 1983).

\section{Capillary suction time (CST)}

The results of CST tests are shown in Fig. 3. The value of CST of the raw chemical sludge was too high to make accurate and complete measurement, limited by the length of videotape used in the experiment. It was estimated best at over $2 \mathrm{~h}$. No significant change was observed even in the presence of polyelectrolyte. The extremely high CST was probably caused by the high solid content and the oil and grease in the sludge. As for the raw waste activated sludge, the CST was $270 \mathrm{~s}$, which was much lower than that of the chemical sludge, indicating that it was easier to be dewatered than the chemical sludge. The optimal dosage was $100 \mathrm{mg} / \mathrm{L}$ and the corresponding CST was $36 \mathrm{~s}$. Any more increase beyond the optimal dosage of polyelectrolyte caused deterioration in the

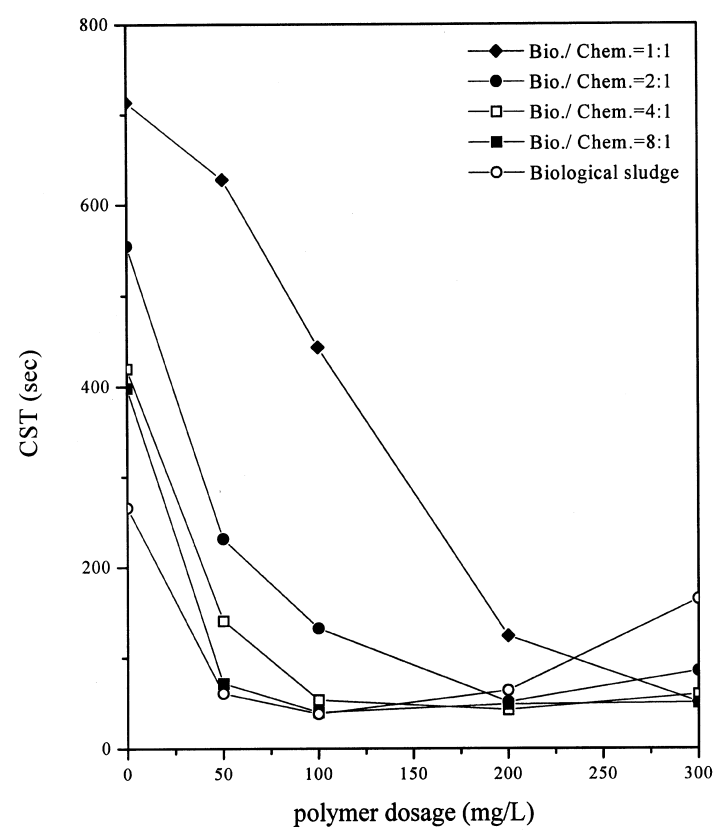

Fig. 3. Capillary suction time (CST) of sludge as a function of polyelectrolyte dosage. dewaterability. For the mixed sludge with volumetric ratio of $1: 1$, the value of CST was originally $720 \mathrm{~s}$. It decreased with increasing polyelectrolyte concentration, and a good dewaterability could be obtained at the polyelectrolyte dosage of $300 \mathrm{mg} / \mathrm{L}$ with the corresponding CST of $48 \mathrm{~s}$. Depending on the mixing ratios, the CST of raw mixed sludge decreased with increasing fraction of waste activated sludge. In addition, the CST of mixed sludge significantly decreased upon the addition of polyelectrolyte. For the mixed sludge with a volumetric ratio of $2: 1$, the optimal dosage was $200 \mathrm{mg} / \mathrm{L}$ and the corresponding CST was 49 s. Similar optimal polyelectrolyte dosage and behaviors were found for the mixed sludge with volumetric ratio of $4: 1$, except that the CST was all lower than those of sludges with higher fraction of chemical sludge. It was also found that for the mixed sludge with volumetric ratio of $8: 1$, the CST as affected by polyelectrolyte showed very similar trend with that of the waste activated sludge, and the optimal dosage was $100 \mathrm{mg} / \mathrm{L}$. It demonstrates that the CST of the chemical sludge is significantly decreased when the chemical sludge is mixed with certain ratios of the waste activated sludge. Meanwhile, the CST of the waste activated sludge definitely increases but only to a limited extent.

It has been found that lower CST values are obtained among the sludge with lower solid content (Sarikaya and Al-Marshoud, 1993; Herwijn et al., 1995). There is a certain limit in the interpretation of CST since the CST is not an intensive property. Therefore, a modified CST has been proposed, taking into account the changes in solid concentration in the sludge, (Dohanyos et al., 1988). It is written as

$$
\mathrm{CST}_{\mathrm{S}}=\left(\mathrm{CST}-\mathrm{CST}_{\mathrm{F}}\right) / \mathrm{C}
$$

where $\mathrm{CST}_{\mathrm{S}}$ stands for the modified CST taking into account the solid content, CST for the measured CST, CST $_{F}$ for the CST of the filtrate, and C for the suspended solid concentration of the sludge. Since the solid content of the chemical sludge is much higher than that of the waste activated sludge, it is probable that the changes in CST are caused by changes in solid content when the chemical sludge is mixed with the waste activated sludge. To evaluate this effect, $\mathrm{CST}_{\mathrm{S}}$ of sludge is assessed in the study. The results are shown in Fig. 4. Though not shown in Fig. 4, it was still the chemical sludge that had the highest $\mathrm{CST}_{\mathrm{S}}$. It was observed that the wasteactivated sludge instead possessed the higher $\mathrm{CST}_{\mathrm{S}}$ than mixed sludge samples. This is because of its low solid content. Besides, CSTs of simple biological sludge shows a different pattern with regard to the polyelectrolyte dose. The drastically different pattern observed for CSTs of biological sludge in Fig. 4 is probably due to the significant difference in solid content between the chemical $\left(83,944 \mathrm{mg} / \mathrm{dm}^{3}\right)$ and waste activated sludges $\left(4308 \mathrm{mg} / \mathrm{dm}^{3}\right)$ as shown in Table 1. The values of $\mathrm{CST}_{\mathrm{S}}$ of mixed sludge samples in the absence of polyelectrolyte decreased with the 


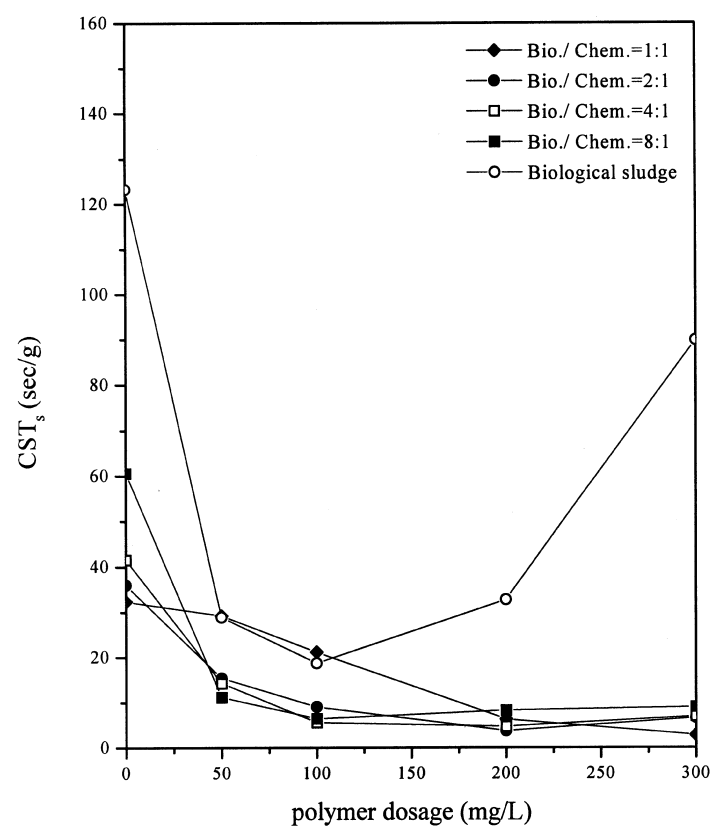

Fig. 4. Modified capillary suction time $\left(\mathrm{CST}_{\mathrm{S}}\right)$ of sludge as a function of polyelectrolyte dosage.

increase in chemical sludge fractions. However, with the addition of polyelectrolyte $\mathrm{CST}_{\mathrm{S}}$ values decreased rapidly to approximately equal value regardless of the mixing ratio. The optimal polyelectrolyte dosage ranged from 100 to $200 \mathrm{mg} / \mathrm{L}$, except the one for mixed sludge with the highest fraction $(1: 1)$ of chemical sludge. It illustrates that even on another basis of comparison the values of $\mathrm{CST}_{\mathrm{S}}$ of mixed sludge are lower than both chemical and waste activated sludges. In addition, not only could the mixed sludge samples be dewatered effectively through polyelectrolyte conditioning, but also less chances of overdosing were observed.

\section{Specific resistance to filtration (SRF)}

The results of SRF tests are shown in Fig. 5. The $\mathrm{SRF}$ of raw chemical sludge was $7.3 \times 10^{16} \mathrm{~m} / \mathrm{kg}$. It decreased with an increase in polyelectrolyte dosage. However, no optimal dosage could be found in the concentration range studied. The SRF of raw wasteactivated sludge was $8.4 \times 10^{15} \mathrm{~m} / \mathrm{kg}$. The optimal cationic polyelectrolyte dosage was $100 \mathrm{mg} / \mathrm{L}$ and the corresponding SRF was $1.4 \times 10^{15} \mathrm{~m} / \mathrm{kg}$. The overdose was found on further increase of the polyelectrolyte dosage. The values of SRF of mixed sludge in the absence of polyelectrolyte $\left(8.0 \times 10^{15}\right.$ to $1.2 \times 10^{16} \mathrm{~m} / \mathrm{kg}$ ) were slightly higher than the SRF of the waste activated sludge, yet were much lower when compared with the SRF of the chemical sludge. For the mixed sludges with the volumetric ratio of $4: 1$ and $8: 1$, the values of SRF were approximately equal to that of the waste activated sludge, and the optimal dosage, ranging from 50 to $100 \mathrm{mg} / \mathrm{L}$, was

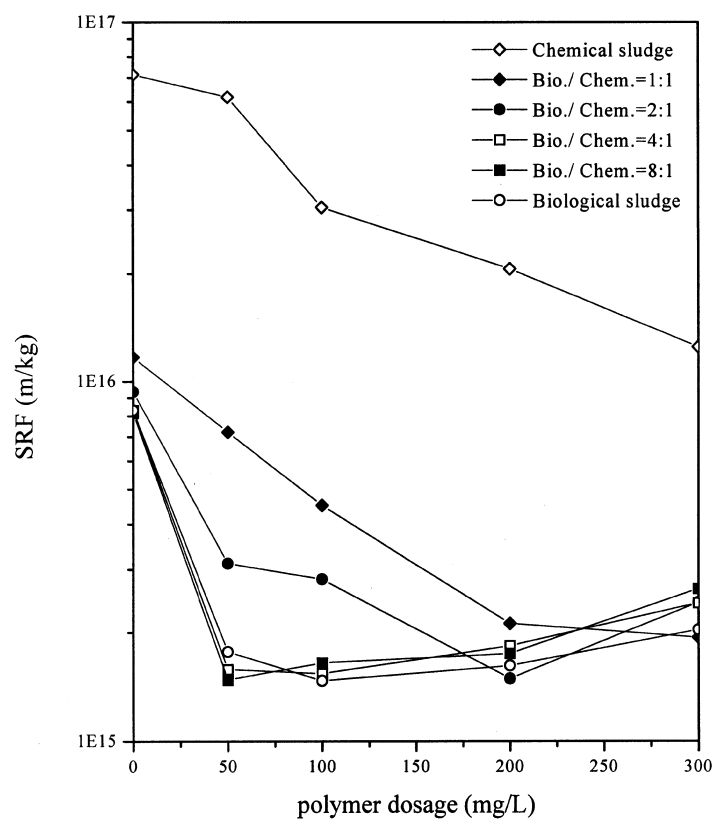

Fig. 5. Specific resistance to filtration (SRF) of sludge as a function of polyelectrolyte dosage.

even lower than that of the waste activated sludge. As the fraction of chemical sludge increased to half of the waste activated sludge, the SRF became higher and the optimal dosage of polyelectrolyte increased to $200 \mathrm{mg} / \mathrm{L}$. Similarly, for the mixed sludge with volumetric ratio of $1: 1$, the SRF was higher, and the optimal dosage was $300 \mathrm{mg} / \mathrm{L}$.

The optimal dosages of the polyelectrolyte as predicted by CST, $\mathrm{CST}_{\mathrm{S}}$, SRF tests, and iso-electric points (IEPs) are shown in Table 2. It is noted that the former three tests utilized all provide very consistent prediction of the optimal dosage. The optimal dosage as predicted from IEPs indicates that the charge neutralization might not be the dominant mechanism in the sludge conditioning. For the waste activated sludge, mixed sludges of mixing ratio of $1: 1$ and $2: 1$, the optimal dosages were 100,300 , and $200 \mathrm{mg} / \mathrm{L}$, respectively. As for the mixed sludges with mixing ratio of $4: 1$ and $8: 1$, the optimal dosages predicted by the CST and CST $_{\mathrm{S}}$ tests were only slightly higher than that predicted by results from SRF. It shows that the optimal polyelectrolyte dosage for mixed sludge with a significant chemical fraction increases two or three times higher. It is noted that when the fraction of the chemical sludge is lower than a certain value, the dewaterability of the mixed sludge is equal to or better than that of the waste activated sludge. Considering the difference in the pressure utilized in the CST $(10-15 \mathrm{KPa})$ and SRF (3000 psi) measurement, the same optimal dosage predicted by the two tests may be a coincidence. However, in a practical viewpoint, it implies that the plant operator can correlate results from the relatively simple CST test to that of the 
Table 2. Optimal dosage $(\mathrm{mg} / \mathrm{L})$ of the polyelectrolyte as predicted by $\mathrm{CST}_{\mathrm{CST}}, \mathrm{CSRF}_{\mathrm{S}}$, tests, and iso-electric points (IEPs)

\begin{tabular}{lrrrr}
\hline Test & \multicolumn{1}{c}{ CST } & \multicolumn{1}{c}{ CST $_{\text {S }}$} & \multicolumn{1}{l}{ SRF } & IEP $_{\text {S }}$ \\
\hline WAS $^{\mathrm{a}}$ & 100 & 100 & 100 & $>300$ \\
$1: 1^{\mathrm{b}}$ & 300 & 300 & 300 & $>300$ \\
$2: 1$ & 200 & 200 & 200 & 100 \\
$4: 1$ & $100-200$ & $100-200$ & $50-100$ & 200 \\
$8: 1$ & 100 & 100 & $50-100$ & $>300$ \\
\hline
\end{tabular}

${ }^{\mathrm{a}}$ Waste activated sludge.

${ }^{\mathrm{b}}$ Mixed sludge with volumetric ratio of waste activated sludge: chemical sludge.

more time-consuming SRF test, and gain more information for the dosage control. We have demonstrated that the chemical sludge was much harder to be dewatered than the waste activated sludge. Nevertheless, when the chemical sludge was mixed with the waste activated sludge at ratios of $1: 1$ and $1: 2$, the dewaterability of the chemical sludge was remarkably improved, while the relatively better dewaterability of the waste activated sludge deteriorated only to a limited extent. As the mixing ratio became $1: 4$ and $1: 8$, the dewaterability of the mixed sludge was equal to or even better than that of the waste activated sludge.

The mechanism of the conditioning and dewatering behaviors of mixed sludge can be elaborated from the viewpoint of the floc structure. As evidenced from the determination of IEPs, the optimal dewatering capacity had already been achieved before the surface charge of the flocs had been completely neutralized. It can be reasoned that the adsorbed polyelectrolyte extends far enough from the floc surfaces to span the distance over which electrostatic repulsion operates (Csempesz et al., 1998). The conditioning of the sludge samples by a polyelectrolyte is thus confirmed as mainly through the bridging that encapsulates rigid and discrete particles into the loose and larger flocs, which are easier to be dewatered (Bohm and Kulicke, 1997). As indicated, successful sludge conditioning requires not only facilitating flocculation, but also reducing cake compressibility (Zall et al., 1987). The addition of inorganic materials to assist the filterability of biological sludge has been practiced widely (Tenney and Cole, 1968; Albertson and Kopper, 1983). The physical conditioners, such as fly ash, fine coal, hydrated lime and slag from cement kiln, are used to deal with the compressible sludge cakes. These relatively inert, inorganic particles are referred as skeleton builders that form a permeable and rigid structure that can remain porous under high pressure (Zall et al., 1987; Benitez et al., 1994). When the fraction of chemical sludge is low, the chemical sludge acts as skeleton builder in the mixed sludge since it is composed of hydroxide and carbonate precipitates of magnesium, calcium and chromium. That is probably the reason why the dewaterability of the mixed sludge is equal to that of the waste activated sludge. In fact, the dewaterability of the mixed sludge may even be enhanced compared with waste activated sludge at a certain mixing ratio. Nevertheless, the dewaterability of the mixed sludge becomes worse as the fraction of chemical sludge reaches a critical value. It is resulted from the fact that the porosity of the floc is reduced and becomes too compact for water to flow through.

\section{Bound water content}

The bound water contents were 1.97 and $1.48 \mathrm{~g} / \mathrm{g}$ dry solid for the waste activated and chemical sludges, respectively (Fig. 6). This is in conformity with previous findings that bound water content in waste activated sludge is higher than in clay sludge (Chu and Lee, 1999). It might be the extracellular polymer that makes the waste activated sludge possess higher bound water content than the chemical sludge (Vesilind and Martel, 1990; Colin and Gazbar, 1995). Another explanation is that since the expression method is used in determining the bound water, the network-like floc of the waste activated sludge tends to be more resilient and elastic under expression. That is why the waste activated sludge had the higher bound water content. The bound water of the mixed sludge ranged between these two values, depending on the mixing ratio. It was found that the bound water content could be significantly decreased as long as the chemical sludge fraction was higher than $20 \%$ (mixing ratio of $4: 1$ ). This coincides with the critical value that the presence of chemical sludge does not affect the dewaterability of the waste activated sludge. Bound water of sludge samples all decreased on the addition of $50 \mathrm{mg} / \mathrm{L}$ of

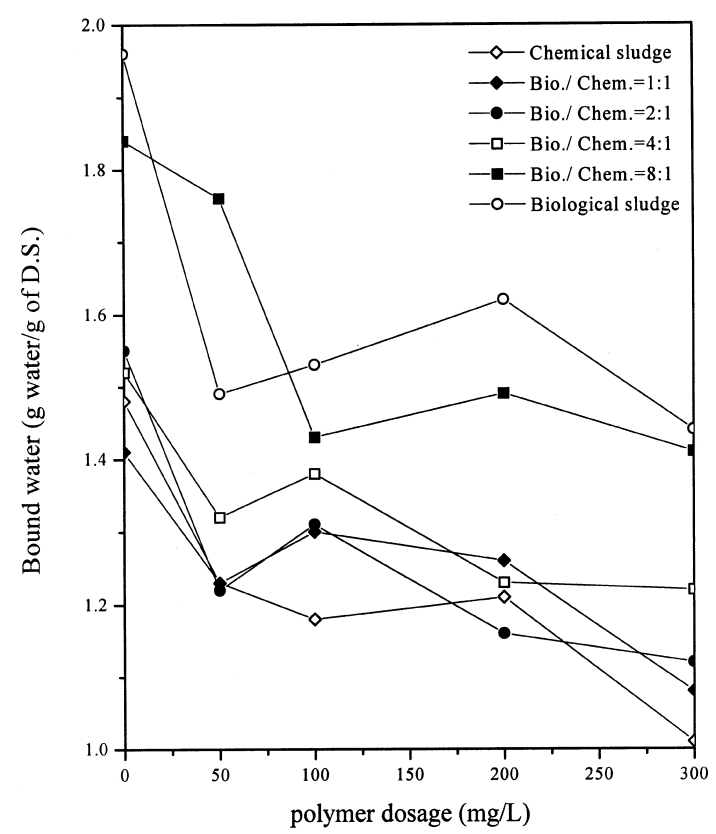

Fig. 6. Bound water content of sludges as a function of polyelectrolyte dosage. 
Table 3. Values of $\mathrm{pH}$ as affected by polyelectrolyte dosage

\begin{tabular}{lccccc}
\hline Dosage $(\mathrm{mg} / \mathrm{L})$ & 0 & 50 & 100 & 200 & 300 \\
\hline Waste activated sludge & 7.25 & 7.37 & 7.38 & 7.38 & 7.38 \\
Chemical sludge & 7.02 & 7.00 & 6.99 & 7.01 & 7.05 \\
$1: 1^{\mathrm{a}}$ & 7.00 & 7.00 & 7.02 & 7.00 & 7.10 \\
$2: 1$ & 7.12 & 7.06 & 7.03 & 7.06 & 7.08 \\
$4: 1$ & 7.14 & 7.09 & 7.11 & 7.11 & 7.16 \\
$8: 1$ & 7.19 & 7.23 & 7.20 & 7.24 & 7.32 \\
\hline
\end{tabular}

${ }^{\text {a }}$ Mixed sludge with volumetric ratio of waste activated sludge: chemical sludge.

polyelectrolyte. For waste activated and mixed sludges with a high waste activated sludge fraction $(8: 1)$, the bound water tended to stabilize and did not decrease on further addition of polyelectrolyte. The polyelectrolyte dosage (100 to $200 \mathrm{mg} / \mathrm{L})$ that resulted in low bound water content agreed well with optimal dosage for dewatering. On the contrary, for the chemical and mixed sludges with significant chemical sludge fractions, the bound water decreased slightly as the polyelectrolyte dosage increased. It has been proposed that the bound water will be decreased on conditioning by the replacement of water molecules with polyelectrolyte on sludge surfaces (Robinson and Knock, 1992; Colin and Gazbar, 1995). Some argue that bound water is not changed on conditioning (Tsang and Vesilind, 1990). It has also been indicated that the bound water content first decreases on polymer addition and then slightly increases at elevated polymer dosage (Chu and Lee, 1999). What we observed in the current study indicated that bound water content decreased at low polyelectrolyte dosage and changed insignificantly at higher polyelectrolyte dosage. Since bound water can be regarded as an index of the affinity between the sludge surfaces and water; the higher the bound water, the harder water is removed by mechanical methods (Vesilind and Martel, 1990; Colin and Gazbar, 1995; Chen et al., 1997). It shows that mixing with chemical sludge decreases the relatively higher bound water of the waste activated sludge. One might argue why biological sludge has highest bound water even though it has best dewaterability? In fact, sludge dewaterability is determined by floc size, floc structure, viscosity, surface characteristics etc. Moreover, the cake and medium blinding could markedly hinder the filtration and reduce the sludge dewaterability. Therefore, the dewaterability of sludge depends not only on the bound water content, but also (may be more significantly) on the compactibility of filter cake in the current work. Comparing one single index, bound water content, may not correlate well with the true sludge dewaterability.

\section{Advantages and disadvantages of co-conditioning}

Combined treatment of different types of sludge can either be beneficial or detrimental. For example, it has been demonstrated that the co-thickening of primary and secondary sludges in a dissolved air flotation thickener can significantly reduce secondary organic loading while concurrently reducing the amount of grit being transferred to sludge digester (Butler et al., 1997). However, it has been indicated that the primary and waste activated sludges should never be mixed together to prevent phosphate from releasing to the liquid phase (Pitman, 1999). Therefore, primary and waste activated sludges are recommended to be thickened in separate units. In the co-conditioning and dewatering of the chemical and the waste activated sludges, possible shortcomings include release of inorganic contaminants from the chemical sludge to the liquid phase, prohibited biological stabilization of the mixed sludge and restricted reuse of sludge as resources. To evaluate the leaching of chromium from the sludge, $\mathrm{pH}$ values of mixed sludge samples were measured and are listed in Table 3. It was found that $\mathrm{pH}$ changed only slightly with polyelectrolyte dosage and was mostly in the neutral range. There was no increase in the concentration of soluble chromium when the chemical sludge was mixed with waste activated sludge. This is in conformity with our previous findings that the release of chromium from tannery sludge is limited under neutral to alkaline conditions (Chuan and Liu, 1996). It is also possible that chromium may be leached out of the sludge through biological reaction. However, the bioleaching effect was insignificant due to the limited reaction time. In fact, the mixing of chemical sludge with waste activated sludge may even facilitate subsequent treatment efficiency. In composting procedures of tannery sludge, some bulking agents, such as straw and municipal refuse, are added to increase the moisture holding capacity of the sludge (Langlais and Shivas, 1989). The added waste activated sludge may act as the bulking agent in the mixed sludge samples. Though knowing that the chemical sludge from the tannery is categorized as a non-hazardous waste, the major drawback of the combined treatment of both chemical and waste activated sludges is the long-term accumulation and possible leaching of chromium when the sludge is for land treatment and disposal. Some techniques that enhance immobilization mechanisms of land may be utilized to control chromium contamination (Martin and Parkin, 1986).

Conventionally, chemical sludge is dewatered together with waste activated sludge with recessed plate pressure filter, or with filter press among tanneries in Taiwan. The advantages of co-conditioning and dewatering of both sludges are obvious. First, as shown in our results, the dewaterability is unaffected and even enhanced through proper control of mixing ratio. Second, capital investment on equipment for sludge conditioning and dewatering is definitely higher for two parallel processes than a single and larger process. The combined treatment of both sludges thus will become more cost-effective. So 
long as there is no release of contaminants from the chemical sludge and no inhibitory effect on biological sludge stabilization, it seems advantageous to cocondition and dewater both chemical and waste activated sludges from the tannery. In fact, this practice might also be applied to other industrial wastewater treatment plants that generate chemical and biological sludges. That will be the topics of our study in the next phase.

\section{SUMMARY}

The chemical sludge from a tannery was found to be very difficult to be dewatered by polyelectrolyte conditioning. The waste activated sludge from the same plant showed a much better dewaterability. When the chemical sludge was mixed with waste activated sludge at volumetric ratios of $1: 4$ and $1: 8$, the dewaterability of the mixed sludge was equal to or better than that of the waste activated sludge. The optimal polyelectrolyte dosage for the mixed sludge was the same as that of the waste activated sludge. Even when the mixing ratios were $1: 1$ and $1: 2$, the dewaterability of the mixed sludge was significantly better than that of the chemical sludge, and slightly worse than the dewaterability of the waste activated sludge. It demonstrates that the dewaterability of the chemical sludge can be enhanced when it is mixed with the waste activated sludge, while the relatively good dewaterability of the waste activated sludge deteriorates only to a limited extent.

The bound water content of the waste activated sludge was higher than that of the chemical sludge, probably due to the presence of the extracellular polymer. The bound water content of the mixed sludge decreased significantly with increasing fractions of the chemical sludge. It was found that the bound water was affected by polyelectrolyte slightly. The polyelectrolyte dosage that resulted in low bound water agreed well with the optimal dosage as predicted from CST and SRF results.

The chemical sludge is proposed to play a role of skeleton builder that enhances the compactibility of the waste activated sludge when the fraction of chemical sludge is low. It appears advantageous to co-condition and dewater chemical and waste activated sludges. Some possible disadvantages were also discussed.

Acknowledgements-The authors thank the National Science Council of Taiwan for financial support of this work, under contract NSC-87-2218-E-011-006, and the assistance from the Chen-Sam Tannery Co.

\section{REFERENCES}

Albertson O. E. and Kopper M. (1983) Fine-coal-aided centrifugal dewatering of waste activated sludge. J. Water Pollut. Control Fed. 55, 145-156.
APHA (1990) Standard Methods for the Examination of Water and Wastewater, 17th ed. American Public Health Association, Washington, DC.

Ates E., Orhon D. and Tunay O. (1997) Characterization of tannery wastewaters for pretreatment-selected case studies. Wat. Sci. Tech. 36, 217-223.

Benitez J., Rodriguez A. and Suarez A. (1994) Optimization technique for sewage sludge conditioning with polymer and skeleton builders. Wat. Res. 28, 2067-2073.

Bohm N. and Kulicke W. M. (1997) Optimization of the use of polyelectrolytes for dewatering industrial sludge of various origins. Colloid Polym. Sci. 275, 73-81.

Bruus J. H., Nielsen P. H. and Keiding K. (1992) On the stability of activated sludge flocs with implications to dewatering. Wat. Res. 26, 1597-1604.

Butler R. C., Finger R. E., Pitts J. F. and Strutynski B. (1997) Advantages of cothickening primary and secondary sludges in dissolved air flotation thickener. Wat. Environ. Res. 69, 311-316.

Chen G. W., Hung W. T., Chang I. L. and Lee D. J. (1997) Continuous classification of moisture content in waste activated sludge. J. Environ. Eng. ASCE 123, 253-258.

Cheremisinoff P. N. (1994) Sludge Management and Disposal. Prentice-Hall, Englewood Cliffs, NJ.

Chu C. P. and Lee D. J. (1999) Moisture distribution in sludge: effects of polymer conditioning. J. Environ. Eng. ASCE 125, 340-345.

Chuan M. C. and Liu J. C. (1996) Release behavior of chromium from tannery sludge. Wat. Res. 30, 932-938.

Christensen J. R., Sorensen P. B., Christensen G. L. and Hansen J. A. (1993) Mechanisms for overdosing in sludge conditioning. J. Environ. Eng. ASCE 119, 159-171.

Colin F. and Gazbar S. (1995) Distribution of water in sludges in relation to their mechanical dewatering. Wat. Res. 29, 2000-2005.

Csempesz F., Nagy M. and Rohrsetzer S. (1998) Characterization and features of competitive polymer adsorption on colloidal dispersion. Colloids Surf. 141, 419-424.

Dohanyos M., Grau P. and Sedlacek M. (1988) Interpretation of dewaterability measurements by capillary suction time (CST). Wat. Sci. Tech. 20, 265-267.

Eckenfelder Jr. W. W. and Musterman J. L. (1994) Treatment and pretreatment requirements for industrial wastewaters in municipal activated sludge plants. Wat. Sci. Tech. 29, 79-88.

Herwijn A. J. M., Heij E. J. L., Ilzermans J. J., Coumans W. J. and Kerkhof P. J. A. M. (1995) Determination of specific cake resistance with a new capillary suction time apparatus. Ind. Eng. Chem. Res. 34, 1310-119.

Jorand E., Zartarian F., Thomas F., Block J. C., Bottero J. Y., Villemin G., Urbain V. and Manem J. (1995) Chemical and structural (2D) linkage between bacteria within activated sludge flocs. Wat. Res. 29, 1639-1647.

Langlais R. J. and Shivas A. J. (1989) A method to convert tannery sludge into a soil extender. J. Am. Leather Chem. Assoc. 84, 14-20.

Martin J. P. and Parkin G. F. (1986) Land treatment of tannery sludge. J. Am. Leather Chem. Assoc. 81, 149-173.

Pitman A. R. (1999) Management of biological nutrient removal plant sludges - change the paradigm?. Wat. Res. 33, 1141-1146.

Robinson J. and Knock W. R. (1992) Use of dilatometric and drying techniques for assessing sludge dewatering characteristics. Wat. Environ. Res. 64, 60-68.

Sarikaya H. Z. and Al-Marshoud S. (1993) Improvement of dewatering characteristics of anaerobically digested sludge. Wat. Sci. Tech. 28, 47-51.

Somasundaran P. and Yu X. (1994) Flocculation/dispersion of suspensions by controlling adsorption and conformation of polymers and surfactants. Adv. Colloid Interface Sci. 53, 33-49. 
Somasundaran P. and Krishnakumar S. (1997) Adsorption of surfactant and polymer at the solid-liquid interface. Colloids Surf. 123-124, 491-513.

Tenney M. W. and Cole T. G. (1968) The use of fly ash in conditioning biological sludge for vacuum filtration. J. Water Pollut. Control Fed. 40, 281-302.

Tsang K. R. and Vesilind P. A. (1990) Moisture distribution in sludge. Wat. Sci. Tech. 22, 135-142.

Tunay O., Orhon D. and Kabdasli I. (1994) Pretreatment requirements for leather tanning industry wastewaters. Wat. Sci. Tech. 29, 121-128.
Vesilind P. A. and Martel C. J. (1990) Freezing of water and wastewater sludge. J. Environ. Eng. ASCE 116, 854-862.

Water Pollution Control Federation (WPCF) (1983) Sludge Dewatering. Manual of practice No. 20, Water Pollution Control Federation, Washington, DC.

Zall J., Galil N. and Bebhun M. (1987) Skeleton builders for conditioning oily sludge. J. Water Pollut. Control Fed. 59, 699-706. 